ORIGINAL ARTICLE

\title{
Experience of our First-Ever Living Donor Liver Transplantation In Hiv-Positive Patient-Report From Developing Country with Literature Review
}

\author{
ABDUL WAHAB DOGAR ${ }^{1}$, KALEEM ULLAH $^{1}$, HAMID RAZA $^{1}$, ALI HUSNAIN ${ }^{1}$, SHAMS-UD-DIN ${ }^{1}$, SYED HASNAIN ABBAS ${ }^{1}$, \\ AMIR HAMZA 1 , AZHAR HUSSAIN ${ }^{1}$ \\ ${ }_{1}$ Pir Abdul Qadir Shah Jelani Institute of medical Sciences, Gambat, Sind, Pakistan \\ Corresponding Author: Azhar Hussain, Pir Abdul Qadir Shah Jelani Institute of medical Sciences, Gambat, Sind, Pakistan, E-mail: \\ azharhussain0139@gmail.com, Phone:+92303-7156931
}

\begin{abstract}
Human Immunodeficiency Virus (HIV) is one of the gravest health challenges worldwide in the present era as it has been for the past 4 decades. HIV has always been a sort of stigma and most clinicians are reluctant to perform liver transplantation for chronic liver disease patients with HIV co-infection. Patients with $\mathrm{CD} 4^{+}$cell count $>100 / \mathrm{ml}$ along with suppressed mRNA levels on PCR, stable HAART regimen, and absence of any AIDS-specific illness or opportunistic infectionsare the requirements for selecting HIV-positive recipients for liver transplantation. We report the first living donor liver transplant in an HIV-positive recipient in a developing country. Here are the details of the case.
\end{abstract}

Keywords: HIV, living donor, Liver transplantation, developing country

\section{INTRODUCTION}

Human Immunodeficiency Virus (HIV) is one of the gravest health challenges worldwide in the present era as it has been for the past 4 decades. The first case of Acquired Immunodeficiency Syndrome (AIDS) was reported in1981 and HIV-1 was isolated from the $1^{\text {st }}$ diseased patient in 1983. ${ }^{1}$ The disease prevalence has been increasing ever since that decade. However, the trend showed a decreasing curve in the last decade with a $23 \%$ decline in new cases in 2019 as compared to 2010. The treatment modalities for treating HIV infection kept changing and upgrading over time. However, the breakthrough was in 1996, when the successful trial of triple combination therapy was reported atthe Vancouver AIDS conference. ${ }^{2}$ After the declaration of the first International AIDS SocietyUSA recommendations for antiretroviral therapy, a substantial decrease in morbidity and mortality has occurred all around the world. ${ }^{3,4}$

Pakistan is a developing country and ranked $154^{\text {th }}$ out of 189 countries in the Human Development Index of the United Nations. According to World Health Organization (WHO), HIV is considered a concentrated epidemic. The prevalence of HIV in Pakistan is less than $1 \%$ with a total number of 150,000 according to the estimation done in 2017. Almost 21,000 new cases were recorded in $2018 .{ }^{5}$

HIV has always been a sort of stigma and most clinicians are reluctant to perform liver transplantation for indicated patients with HIV co-infection, even though the transplantation has been done in different parts of the world in HIV-positive recipients. ${ }^{6}$ CD4 ${ }^{+}$cell count $>100 / \mathrm{ml}$ is considered to be safe enough to perform liver transplantation. Besides adequate $\mathrm{CD}^{+}$cell count, the other requirements for selecting HIV-positive recipients in liver transplantation include suppressed mRNA levels, stable Highly Active Antiretroviral Therapy (HAART) regimen, and absence of any AIDS-specific illness or opportunistic infections. ${ }^{6,7}$

We performed the $1^{\text {st }}$ living donor liver transplant in an HIV-positive patient in our country. Here, are the details of the case.
Case Presentation: A 58-year-old married gentleman, a journalist by profession, presented in the outdoor patient department of Pir Abdul Qadir Shah Jeelani Institute of Medical Sciences Hospital, Gambat, Pakistan with complaints of general weakness and fatigue. A detailed history was taken and medical records were reviewed. He was a known case of Hepatitis B virus (HBV) related chronic Liver disease for the last 14 years. He had multiple episodes of upper gastrointestinal bleeding in the past for which multiple times banding was done. The patient was already on antiviral therapy. CT scan Abdomen of the patient showed findings of early chronic liver disease with no evidence of hepatocellular carcinoma (HCC). The patient was advised to continue antiviral therapy with a threemonth follow-up.

On subsequent follow-ups, he came out to be HIV-1 positive on ELISA screening. HIV PCR showed a high titer. The patient was referred to the infectious disease clinic for treatment. He was started on antiretroviral drugs i.eHAART therapy. Few months after treatment hisHIV viral PCR load titer came to a minimum level.

Table 1: Laboratory investigations of the patient

\begin{tabular}{|l|l|l|}
\hline Laboratory & Result & $\begin{array}{l}\text { Reference } \\
\text { Values }\end{array}$ \\
\hline Total bilirubin(mg/dl) & 2.1 & $1.2-2$ \\
\hline Albumin(g/dl) & 2.5 & $3.4-5$ \\
\hline Creatinine $(\mathrm{mg} / \mathrm{dl})$ & 1.0 & $0.5-1.3$ \\
\hline $\mathrm{Na}^{+}$level & 135 & $135-145$ \\
\hline INR & 1.9 & \\
\hline Hemoglobin(g/dl) & 7.9 & $11.5-15$ \\
\hline WBCs(cells/mm3) & $2.16 \times 10^{3}$ & $4000-11000$ \\
\hline Platelet count(cells/mm3) & 47 & $150-400 \times 10^{9}$ \\
\hline AFPng/mL & 197.1 & $10 \mathrm{ng} / \mathrm{mL}$ to 20 \\
\hline Ascites & $\begin{array}{l}\text { Moderate } \\
\text { to Severe }\end{array}$ \\
\hline PSE & None & \\
\hline Child Score & Class c & \\
\hline MELD Score & 26 & \\
\hline
\end{tabular}

(Abbreviations: INR, International normalized ratio; WBC, White blood cell; AFP, Alpha fetoprotein; PSE, Portosystemic encephalopathy; MELD, Model for end stage liver disease). 
Meanwhile,his chronic liver disease progressed and his condition got worsened. A Follow-up CT scan of the Abdomen showed a shrunken irregular liver measuring $12.5 \mathrm{~cm}$ in size with hypertrophy of the caudate lobe. The portal vein was dilated measuring $16.0 \mathrm{~mm}$ with no evidence of thrombus. Spleen was enlarged measuring $20.5 \mathrm{~cm}$. Abdomen CT also showed moderate ascites with two HCC lesions of size of $2^{\star} 2 \mathrm{~cm}$ and $2.5^{\star} 2 \mathrm{~cm}$ size respectively. (Fig. 1 and 2). Routine Labs reports are shown in table 01 . His Child pugh scoring was $10 \mathrm{C}$.

Due to non-detectable HIV RNA levels on PCR and $\mathrm{CD}^{+}$cell count of $>375 / \mathrm{ml}$, he was planned for liver transplantation.

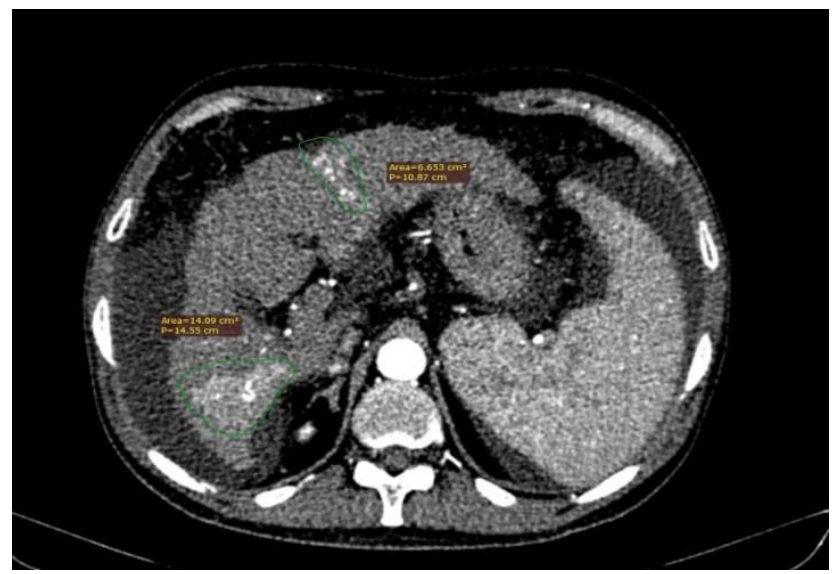

Fig. 1: CT Abdomen (Arterial phase) showing HCC nodules

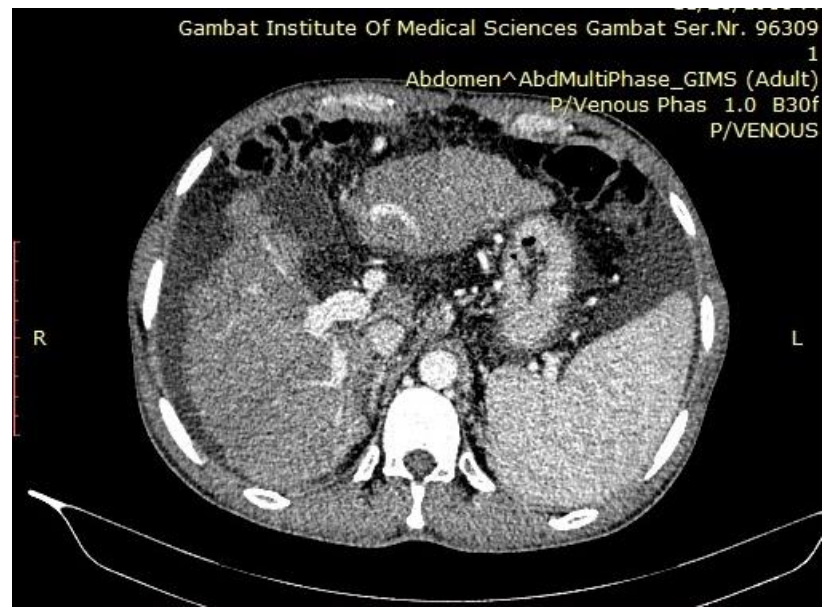

Fig. 2: CT scan Abdomen (Porto-venous phase) showing cirrhotic liver with patent portal vein

Living donor liver transplantation was done. The donor was the daughter of the patient. The donor was selected according to our selection criteria. ${ }^{8}$ The right lobe without middle hepatic vein was transplanted. Graft weight was $480 \mathrm{gm}$, having a single right hepatic duct, right portal vein, and right hepatic vein. Intraoperative Doppler ultrasound showed patent hepatic vasculature. The patient was shifted to ICU and was kept on mechanical ventilationand was extubated the next morning after confirmatory Doppler ultrasound for hepatic vasculature patency. Immunosuppressant therapy was also started with tacrolimus and steroids on the first post-operative day. HAART therapy was also resumed on 1st post-operative day. The patient remained in ICU for 04 days and was shifted toward then. He was discharged on the $10^{\text {th }}$ postoperative day in a stable condition. On 6 months follow-up, he was fine and all the lab reports were in the normal range.

\section{DISCUSSION}

Certain studies have suggested that before the introduction of HAART therapy, end-stage liver disease was the leading cause of death in HIV-positive patients. HIV-positive patients with co-infection of $\mathrm{HCV} / \mathrm{HBV}$ are more susceptible to develop liver fibrosis. HIV infection was considered a contraindication for liver transplantation in the pre-HAART era. However, after the introduction ofhighly effective Anti-viral drugs, liver transplantation in HIVpositive recipients yields a goodoutcome. Although, the advanced pharmacological options may be good enough for the treatment of chronic hepatitis, but can not reverse decompensation. Liver transplantation is the only suitable option for end-stage liver disease. ${ }^{9}$

Liver transplant centers in most of the developing countries do not offer liver transplantation to HIV infected even if these patients fulfill the criteria for transplantation. The reasons and major hurdle for Living donor liver transplantation in HIV-positive recipients in this part of the world are the ethical considerations of donors and lack of awareness in medical as well as common people. HIVinfected patients are considered a stigma in this region and like other developing countries. Most of the medical personnel and donors are highly reluctant toward helping these people.Our liver transplant Centre was $1^{\text {st }}$ in the country where HIV-positive recipients were considered for liver transplantation while meeting the proper selection criteria. The surgery went successful without any intraoperative complications and we started the patient on his antiretroviral regimens the very next day of transplantation.

Theoretically, in HIV-infected patients, there is a comparatively greater risk of opportunistic infections when these patients are put on immunosuppressive drugs after transplantation. This is one of the other reasons due to which these patients are not encouraged for liver transplantation but studies have reported safe outcomes of transplantation in such patients with the use of postoperative immunosuppressant therapy. ${ }^{10,}{ }^{11}$ However, our patient did not develop any postoperative opportunistic infection and remained stable till the last follow-up.

Another concern for HIV-infected patients is the pharmacodynamics interaction between anti-retroviral and immunosuppressive regimens. Protease inhibitors and Non nucleoside reverse transcriptase inhibitors (NNRTIs) can induce or inhibit cytochrome-P450 metabolism in the liver which can potentially affect the concentrations of immunosuppressant drugs in the blood. ${ }^{12}$ Nevertheless, these interactions are not of much significance as this can be prevented by thorough monitoring of the plasma drug concentrations ${ }^{12}$.

Our patient showed normal recovery as like other liver transplant recipients. The six-monthly follow-up of the 
patient showed no evidence of any postoperative complication.

As is evident from our case, we strongly recommend liver transplantation for HIV infected patients with endstage liver disease and they should be considered equally good candidates for liver transplantation as other HIV negative recipients provided that the patients have a sufficient level of $\mathrm{CD}^{+}$cell count (at least greater than 100 cells $/ \mathrm{ml}$ ) with suppressed HIV mRNA levels on PCR and no evidence of any of the AIDS-defining opportunistic infection.

Registration of research studies: N/A.

Consent: Written informed consent was obtained from the patient for publication of this case report and accompanying images. A copy of the written consent is available for review by the Editor-in-Chief of this journal on request.

Declaration of competing interest: None declared.

\section{REFERENCES}

1. Centers for Disease Control (CDC). Kaposi's sarcoma and Pneumocystis pneumonia among homosexual men: New York City and California.Morb Mortal Wkly Rep1981; 30:305-308.

2. Vella, Stefanoa; Schwartländer, Bernardb; Sow, Salif Papac; Eholie, Serge Pauld; Murphy, Robert L.e The history of antiretroviral therapy and of its implementation in resourcelimited areas of the world, AIDS: June 19, 2012 - Volume 26 Issue 10 - $p$ 1231-1241 doi: 10.1097/QAD.0b013e32835521a3

3. Carpenter CC, Fischl MA, Hammer SM, Hirsch MS, Jacobsen DM, Katzenstein DA, et al. Antiretroviral therapy for HIV infection in 1996. Recommendations of an international panel. International AIDS Society-USA. JAMA 1996; 276:146-154. Review.

4. Palella FJ Jr, Delaney KM, Moorman AC, Loveless MO, Fuhrer J, Satten GA, et al. Declining morbidity and mortality among patients with advanced human immunodeficiency virus infection. HIV Outpatient Study Investigators. N Engl J Med1998; 338:853-860.

5. The Global HIV/AIDS Epidemic. U.S. Department of Health \& Human Services. Accessed at March 30,2021: https://www.hiv.gov/hiv-basics/overview/data-andtrends/global-statistics.

6. Harbell, J., Terrault, N. A., \& Stock, P. (2013). Solid organ transplants in HIV-infected patients. Current HIV/AIDS reports, 10(3), 217-225. https://doi.org/10.1007/s11904-0130170-z

7. Fung J, Eghtesad B, Patel-Tom K, DeVera M, Chapman H, Ragni M. Liver transplantation in patients with HIV infection. Liver Transplantation. 2004 Oct;10(S10):S39-53.

8. Ullah K, Dogar AW, Uddin S, Hasnain S, Ahmad B, Ghaffar A. Frequency and Outcome of Hepatic Arterial Thrombosis in Recipients of Living Donor Liver Transplantation. J Coll Physicians Surg Pak. 2021 Aug;31(8):897-902. doi: 10.29271/jcpsp.2021.08.897. PMID: 34320704

9. Camino X, Iribarren JA, Arrizabalaga J, Rodríguez F, Von Wichmann AM. Causes of mortality among patients infected with the human immunodeficiency virus in the era of high active antiretroviral therapy. Enferm Infecc Microbiol Clin 2001; 19: 85-86.

10. Stock PG, Roland ME, Carlson L, Freise CE, Roberts JP, Hirose R, et al. Kidney and liver transplantation in human immunodeficiency virus-infected patients: a pilot safety and efficacy study. Transplantation2003; 76: 370-375.

11. Braitstein P. HIV infection and liver transplantation: A review of the literature. BRITISH COLUMBIA MEDICAL JOURNAL. 2004;46(1):14-5.

12. Jain AK, Venkataramanan R, Fridell JA, Gadomski M, Shaw LM, Ragni M, et al.Nelfinavir, a protease inhibitor, increases sirolimus levels in liver transplantation patient: a case report. Liver Transpl2002; 8: 838-840.

13. Moreno, S., Fortún, J., Quereda, C., Moreno, A., Pérez-Elías, M.J., Martín-Dávila, P., de Vicente, E., Bárcena, R., Quijano, Y., García, M., Nuño, J. and Martínez, A. (2005), Liver transplantation in HIV-infected recipients. Liver Transpl, 11: 76-81. https://doi.org/10.1002/lt.20318 